Las Torres de Lucca. Revista internacional de filosofía política

ISSN-e: 2255-3827

\title{
Demostración, democracia intermitente y sorteo. Tres respuestas de Rancière al problema de la participación política ${ }^{1}$
}

\author{
Alfredo Sánchez Santiago² \\ Recibido: 15-4-2021 / Aceptado: 5-12-2021 / Publicado: 30-01-2022
}

Resumen. En algunas de sus intervenciones teóricas, Jacques Rancière ha puesto de manifiesto sus reticencias con respecto al tema de la participación política, frecuentemente movilizado en las teorías contemporáneas de la democracia como uno de los factores explicativos de la crisis de la representación (que sería debida a un déficit de participación) o como un instrumento adecuado para repararla (mediante un suplemento de participación). En la base de esta reticencia parece subyacer la sospecha de que el tema de la participación acentúa la confusión entre democracia y representación, refrenda el sistema representativo sin cuestionar sus fundamentos y rebaja la fuerza disruptiva de la acción democrática, que queda privada de su capacidad polémica para visibilizar objetos y sujetos excluidos de los marcos consensuales de percepción. Sin embargo, la obra de Rancière contiene al mismo tiempo una noción positiva de participación política desvinculada de la lógica de la representación, y, en intervenciones muy recientes, el autor francés llega incluso a reconocer el valor de ciertos procedimientos de movilización ciudadana y democratización de las instituciones, como la herramienta del sorteo. El objetivo de este trabajo es registrar el acercamiento ambivalente de Rancière al problema de la participación política y resituar los distintos niveles de su argumentación en uno de los temas centrales de su pensamiento: la relación conflictiva entre la acción democrática (política) y las formas instituidas del poder (policía).

Palabras clave: Demostración; democracia intermitente; sorteo; participación política; poder; policía; política; Foucault.

[en] Demonstration, intermittent democracy and sortition. Rancière's three responses to the problem of political participation

\begin{abstract}
In some of his theoretical interventions, Jacques Rancière has been reluctant to the issue of political participation, frequently mobilized in contemporary theories of democracy as one of the explanatory factors of the crisis of representation (which would be due to a participation deficit) or as a suitable instrument to repair it (through a participation supplement). At the base of this reluctance, there seems to be the suspicion that the issue of participation accentuates the confusion between democracy and representation, endorses the representative system without questioning its foundation and reduces the disruptive force of democratic action, which is deprived of its polemical capacity to make visible objects and subjects excluded from the consensual frames of perception. However, at the same time, Rancière's work contains a positive notion of political participation detached from the logic of representation, and, in very recent interventions, the French author even goes so far as to recognize the value of certain procedures of citizen mobilization and democratization of institutions, such as the lottery. The aim of this work is to identify Rancière's ambivalent approach to the problem of political participation and to analyze the different levels of his argumentation through one of the central themes of his thought: the connection between democratic action (politics) and instituted forms of power (police).
\end{abstract}

Keywords: Demonstration; Intermittent Democracy; Lottery; Political Participation; Power; Police; Politics; Foucault.

Cómo citar: Sánchez Santiago, A. (2022). Demostración, democracia intermitente y sorteo. Tres respuestas de Rancière al problema de la participación política. Las Torres de Lucca. Revista internacional de filosofía politica, 11(1), 103-116. https:// dx.doi.org/10.5209/1td1.77046

"Les usages de la démocratie" es uno de los siete trabajos que componen Aux bords du politique, una obra de recopilación de intervenciones de Rancière de finales de la década de los ochenta y principios de los noventa. La primera edición de este libro se publicó en 1990, en un contexto en el que los debates intelectuales derivados del

Esta investigación se ha llevado a cabo en el marco de una estancia predoctoral en la Universidad de Paris VIII Vincennes-Saint-Denis financiada con una ayuda para estancias breves de contratados predoctorales de la UCM.

Algunas de las ideas presentadas en el tercer capítulo fueron discutidas en las octavas Rencontres doctorales del Centre Michel Foucault, organizadas en la Abadía de Ardenne de Caen (Francia) entre el 11 y el 13 de septiembre de 2019. Mi agradecimiento a Judith Revel, Philippe Sabot, Orazio Irrera y al resto de participantes por sus observaciones.

2 Departamento de Filosofía y Sociedad, Facultad de Filosofía, Universidad Complutense de Madrid, España.

Correo electrónico: alfredo.sanchez@ucm.es

ORCID: https://orcic.org/0000-0002-5129-3662.

Las Torres de Lucca. 11 (1), 2022: 103-116 
68 habían quedado ya definitivamente desplazados por los fenómenos específicos de la nueva coyuntura política: globalización neoliberal, declive de las soberanías nacionales, ascenso de las demandas identitarias, contracción de los antagonismos sociales, diseminación de la actividad militante, despliegue de las políticas humanitarias, etc. (Keucheyan, 2017). El texto en cuestión es indicativo del nuevo período en el que ingresa la teoría crítica a finales de la década de los ochenta, de la transformación de su discurso y sus objetos, y puede considerarse un texto de transición en la producción intelectual de Rancière, uno de los primeros en los que el pensador francés recurre al archivo obrero y a las fuentes clásicas de la tradición filosófica para analizar la idea democrática en la sociedad contemporánea. Se trata, en cierto modo, del primer simulacro de La Mésentente, publicado nueve años más tarde.

El origen del texto es una conferencia pronunciada en Santiago de Chile en 1986 en el marco del coloquio "Democracia, democracia social y participación," una de las actividades organizadas por el Centro de estudios de la realidad contemporánea (CERC) como resultado de la red de intercambio establecida desde el año anterior entre la academia chilena y varios centros franceses de enseñanza superior, entre los que figuran la Universidad de París VIII — de la que Rancière es profesor desde 1969- y el Collège International de Philosophie —en el que dirige el programa "Représentations, Récits, Savoirs" desde 1986 hasta 1992_. En un artículo reciente, Patrice Vermeren se ha referido a las difíciles condiciones bajo las que estaban obligados a desarrollarse estos primeros encuentros franco-chilenos, necesariamente al margen de la institución universitaria, en la semiclandestinidad de "los locales sombríos y estrechos" del CERC, en un país sometido todavía a una dictadura militar que interrumpió "toda filosofía digna de ese nombre en la universidad de Chile, que solamente conservó su nombre, pero traicionó su concepto" (Vermeren, 2018). La primera edición de "Les usages de la démocratie" completa la indicación de Vermeren con una breve nota en la que Rancière aclara que su reflexión se produce en el contexto "de una discusión con amigos latinoamericanos confrontados con las esperanzas y dificultades del retorno a la democracia," una discusión encaminada a "la reinterpretación de la experiencia democrática más allá de los estereotipos, teórica y políticamente desastrosos, de la democracia 'real' y la democracia 'formal'” (Rancière, 1990).

En efecto, como todas las reflexiones de Rancière sobre la política, esta puede considerarse una intervención coyuntural, condicionada por la circunstancia global y local en la que se produce. ${ }^{3}$ En "Les usages de la démocratie," la circunstancia parece encauzar su reflexión hacia un interrogante que sigue siendo el nuestro, y que podríamos formular del siguiente modo: ¿a qué democracia podemos aspirar hoy, en un momento de rearme ideológico de las políticas conservadoras y repliegue masivo de la iniciativa popular? ¿Cómo puede concebirse una reactivación de la idea democrática cuando, por una parte, en varias latitudes del planeta se sigue luchando por ella y, por otra, se impone con una fuerza cada vez mayor un discurso que la percibe $y a$ realizada en la alianza del consenso postideológico y la economía de mercado? ¿Es posible restituir a la noción de democracia su potencia originaria sin necesidad de reconducir la oposición ya gastada entre democracia formal y democracia real, entre la escena ilusoria de la representación y el auténtico gobierno del démos?

En el último tramo del texto, Rancière trata de dar respuesta a estos interrogantes marcando sus distancias con respecto al tema de la participación política. Citamos el pasaje in extenso:

Je me demande pourtant si cette notion [de participación] qu'on donne comme solution aux problèmes de la démocratie n'est pas plutôt une solution aux problèmes de sa critique, la menue monnaie des grandes alternatives déchues. L'idée de la participation mêle deux idées d'origine différente : l'idée réformatrice des médiations nécessaires entre le centre et la périphérie et l'idée révolutionnaire de l'activité permanente des sujets citoyens dans tous les domaines. Le mélange des deux produit cette idée bâtarde qui donne comme lieu d'exercice à la permanence démocratique le remplissage des espaces vides du pouvoir. Mais la permanence de la démocratie, n'est-ce pas bien plutôt sa mobilité, sa capacité de déplacer les lieux et les formes de la participation ? (...) La garantie de la permanence démocratique, ce n'est pas le remplissage de tous les temps morts et les espaces vides par les formes de la participation ou du contre-pouvoir ; c'est le renouvellement des acteurs et des formes de leurs actions, c'est la possibilité toujours ouverte d'émergence nouvelle de ce sujet à éclipses. Le contrôle de la démocratie ne peut cesser d'être à son image, versatile et intermittent, c'est-à-dire confiant (2004a, pp.110-111). ${ }^{4}$

La observación puede resultar llamativa: ¿no es Rancière, después de todo, uno de los pensadores contemporáneos que ha dedicado esfuerzos más decididos a democratizar el capital político, uno de los que

Sobre la noción de circunstancia como operador de la reflexión política, cf. Rancière (2009, p. 14).

Traducción: Me pregunto, sin embargo, si esta noción [de participación] que se propone como solución a los problemas de la democracia no es, más bien, una solución a los problemas de su crítica, el resultado de la desaparición de las grandes alternativas. El tema de la participación combina dos ideas de distinto origen: la idea reformista de las mediaciones necesarias entre el centro y la periferia y la idea revolucionaria de la actividad permanente de los sujetos ciudadanos en todos los dominios. La mezcla de las dos produce esta idea bastarda que asigna, como lugar de efectividad de la permanencia democrática, la ocupación de los espacios vacíos del poder. Pero la permanencia de la democracia, ¿no consiste más bien en su movilidad, en su capacidad para desplazar los lugares y las formas de la participación? (...) La garantía de la permanencia democrática no consiste en rellenar todos los tiempos muertos y los espacios vacíos mediante formas de participación o contrapoder; consiste en la renovación de los actores y sus formas de acción, en la posibilidad siempre abierta de que emerja nuevamente ese sujeto formado a base de eclipses. El control de la democracia solo puede ser, como ella misma, versátil e intermitente, es decir, cargado de confianza. 
ha defendido con mayor rotundidad la existencia de una competencia política igual en todos los individuos, de una capacidad humana universal para ocuparse de los asuntos comunes sin necesidad de figuras tutelares ni títulos naturales o adquiridos? El tema de la participación, ¿acaso no viene a incidir precisamente en estas cuestiones, en la posibilidad de que todos los individuos sin distinción intervengan activamente en procesos de deliberación y en instancias de decisión que conciernen a la organización de la vida en comunidad?

En realidad, las reticencias de Rancière hacia el tema de la participación se deducen coherentemente de los presupuestos fundamentales de su pensamiento sobre la política. Desde el comienzo de su producción intelectual, y especialmente a partir de la década de los noventa, el autor francés ha articulado una teoría radical que identifica la política con la democracia, opone la democracia a la representación y define la primera como una actividad autónoma con respecto a las formas instituidas del poder. Si existe un modo de participación acorde con la idea democrática, este no consiste en reaccionar al poder o en vigilar sus posibles excesos. Tampoco en ocupar los "tiempos muertos" y los "espacios vacíos" que deja libres en el curso de su ejercicio o en intervenir allí donde el poder instituido habilita espacios para la intervención popular. La participación democrática consiste más bien en la formación imprevisible y en la renovación constante de un sujeto colectivo que altera y reorganiza un orden sensible de distribución de los cuerpos. La participación democrática, como la democracia misma, es intermitente y fugaz: ahí radica, según Rancière, no tanto su debilidad cuanto su fuerza disruptiva y su capacidad de transformación del orden social.

Precisamente por esta razón, la inclusión de Rancière en un número monográfico sobre filosofía de la participación política exige algunas aclaraciones, pues suele considerarse que el problema de la participación se encuentra analíticamente comprendido en el tema de la representación institucional y que, por consiguiente, solo tiene sentido analizarlo como uno de los factores determinantes de la crisis contemporánea de la representación (que sería debida a un déficit de participación) o como el instrumento adecuado para repararla (mediante un suplemento de participación de la ciudadanía en las instituciones). Y podría pensarse que, sobre estas cuestiones, poco tiene que decir un autor como Rancière, que opone por principio la democracia y la representación y considera la vita democratica como un proceso que posee una racionalidad específica, independiente del Estado y sus instituciones. La imagen habitual de un Rancière "anarquista" e indiferente hacia las formas jurídico-políticas, afianzada por lecturas como la de Todd May (2008; 2016), no ha contribuido tampoco a incluir el pensamiento político rancieriano en este tipo de discusiones.

Frente a este punto de vista, este trabajo defiende que el enfoque de Rancière proporciona un rédito teórico no desdeñable en el análisis filosófico de la participación política. En primer lugar, porque contribuye a elaborar una noción original de participación política no directamente tributaria del problema de la representación y otros temas afines: la legitimidad del poder, la fabricación del consentimiento, la consistencia del vínculo social, el apego de los ciudadanos hacia las instituciones o la reforma de los aparatos de Estado. Captando la iniciativa política de la ciudadanía como una acción no codificada de antemano por el poder institucional, el objetivo de Rancière es subrayar la dimensión práctica de la política y revitalizar la tradición específicamente democrática de la democracia moderna (igualdad, soberanía popular, identidad entre gobernantes y gobernados), históricamente obliterada por la tradición liberal. ${ }^{5}$

En segundo lugar, la cuestión de la participación política permite adoptar un punto de vista más concreto sobre el paradigma rancieriano de lo político. Por un lado, permite reelaborar conceptualmente su definición de la política como una manera de pensar el problema de la participación [avoir part] de las partes [parties] en la comunidad, y, muy especialmente, como una manera de pensar la participación paradójica de los sujetos que carecen de participación [la part des sans-part] en un determinado reparto [partage] de las posiciones sociales. Asimismo, la noción de participación puede ser comprendida como un operador conceptual que hace posible concretar y conectar las esferas de la política y la policía, que algunos comentaristas han criticado por su excesiva abstracción. ${ }^{6}$ Las tres figuras de la participación analizadas en este trabajo (demostración, democracia intermitente y sorteo) constituyen tres maneras distintas de pensar el vínculo entre la acción popular y las formas instituidas del poder, tres maneras de sortear la alternativa entre una visión vertical-institucionalista y una visión puramente anárquica-espontaneísta de los procesos políticos.

En las líneas que siguen proponemos reconstruir la argumentación de Rancière sobre el tema de la participación política partiendo de sus primeros desarrollos sobre la emancipación obrera. Abordamos a continuación sus tesis sobre la política de la década de los noventa y, finalmente, damos cuenta de las modificaciones que algunas de sus obras recientes introducen en sus posicionamientos previos.

\section{El concepto de demostración}

Al menos en este aspecto, la perspectiva de Rancière es afín a la de Chantal Mouffe (2012). Sobre la importancia de la acción en el pensamiento político de Rancière, puede consultarse los trabajos de Christian Ruby $(2007 ; 2009)$.

Me parece especialmente consistente la crítica de Bruno Bosteels (2006), quien considera que, a pesar de sus esfuerzos, Rancière no ha sido capaz de mantener la tensión entre ambas esferas y ha acabado cediendo a las "tentations du gauchisme spéculatif et ses oppositions duelles [tentaciones del izquierdismo especulativo y sus oposiciones duales]" (p. 65) El filósofo belga echa en falta en los textos políticos de Rancière una adecuada historización del pensamiento, una descripción concreta de los modos determinados de inscripción de la política en el orden policial. 
Rancière dedica un período importante de su formación intelectual a explorar el archivo obrero. Este trabajo comienza en torno a 1973. Desde la publicación en 1969 de un texto crítico con el concepto althusseriano de ideología, Rancière se distancia de las coordenadas teóricas de su maestro en la École Normale Supérieure y renueva sus posiciones teóricas en base a dos aportaciones distintas: el maoísmo y el pensamiento de Foucault. La experiencia del 68 y un breve período de militancia en la Gauche prolétarienne, entre 1969 y 1972, instalan en el joven Rancière una preferencia por las ideas inmediatas de los actores sociales, en detrimento de las racionalizaciones abstractas de sus portavoces —intelectuales o vanguardias militantes-. La relación con Foucault durante esos mismos años le permite reconsiderar la función política de los intelectuales y abre ante él una manera insospechada de hacer filosofía, una forma inédita de conectar la teoría con la vida cotidiana y de comprender la historia como un dispositivo de desfundamentación de las prácticas sociales contemporáneas. En un primer momento, Rancière se acerca al archivo obrero desde esta doble sensibilidad. Siguiendo las premisas maoístas, su objetivo es desentrañar, en los primeros tiempos de la emancipación proletaria, los indicios de una palabra obrera autónoma, todavía no contaminada por el discurso marxista ni por los aparatos políticos y sindicales. Aplicando a su manera la arqueología foucaultiana, se trata al mismo tiempo de señalar, en contra de la historiografía marxista, la heterogeneidad irreductible de las revueltas populares, los desfases, las contradicciones y las discontinuidades que impiden identificar en la clase obrera una formación monolítica cohesionada en torno a una ideología, una cultura o un conjunto de prácticas determinado.

Esta indagación arqueológica acerca del movimiento obrero, que aquí nos limitamos a presentar en su aspecto más general sin atender a las transformaciones sucesivas que experimenta hasta La Nuit des prolétaires (1981/2012a), ${ }^{7}$ provoca una inflexión decisiva en el pensamiento del joven Rancière y proporciona el fundamento material de algunas de sus tesis más conocidas de la década de los noventa. En concreto, en esta arqueología toma forma una noción que Rancière no eleva a concepto filosófico hasta "Les usages de la démocratie," pero que constituye una pieza clave de su estudio sobre la emancipación obrera y que será igualmente fundamental en sus desarrollos posteriores sobre la política. Se trata de la noción de demostración. El concepto de demostración es el signo bajo el que se desarrolla su primera conceptualización de la participación política.

Rancière juega con las tres acepciones que recibe el término démonstration en francés: una demostración es una argumentación racional, una determinada distribución de los datos sensibles y una exhibición de capacidad. En una acción política que merezca ser calificada como tal, como algo diferente de un disturbio más o menos espectacular o de una reordenación de las partes sociales existentes, lo que se pone en juego es una demostración en este triple sentido. El asunto se aprecia con claridad en una de las múltiples escenas de la emancipación obrera que Rancière despliega en sus textos: el conflicto de los sastres de París con el señor Schwartz.

En 1833, los sastres parisinos se declaran en huelga (Rancière, 2004a, p. 84ss.; 2012a, p. 53ss.). Reclaman poder negociar su salario y su jornada de trabajo, la posibilidad de leer el periódico durante los tiempos de descanso y otras muestras de consideración mucho más concretas, como la obligación para los patrones de retirar su sombrero al entrar en el taller. El señor Schwartz, jefe de la patronal, se niega a escuchar las razones de los sastres insurgentes. Se niega a escucharlas porque, para él, no hay nada relevante que escuchar, ninguna palabra susceptible de ser tomada en cuenta como expresión de racionalidad, ningún sujeto racional capaz de emitirla. Desde el punto de vista de la lógica desigualitaria en la que se inscribe su razonamiento, la negativa del señor Schwartz está al fin y al cabo fundada: puesto que los obreros no superan para él el umbral de humanidad, los sonidos que salen de sus bocas solo pueden expresar necesidad, placer o displacer, pero no inteligencia; a oídos de Schwartz, la palabra de los obreros, como las máquinas del taller, producen solamente ruido.

Y, sin embargo, la Constitución francesa aprobada tres años antes indica en su preámbulo que todos los franceses son iguales ante la ley. La igualdad existe entonces en alguna parte, por muy frágil e ideal que pueda ser esa existencia. Por lo tanto, lo que corresponde a los obreros es verificarla, llevarla a efecto bajo la forma de una demostración. En concreto, esta demostración consiste - consistió para estos obreros- en argumentar la justicia de las tarifas que proponen a sus patrones, en comentar los textos de sus adversarios para demostrar que están infundados, en exhibir su capacidad para hacerse cargo autónomamente del funcionamiento del taller. Para los obreros, la demostración consiste en demostrarse a sí mismos y en demostrar a sus patrones que son iguales que ellos -iguales en dignidad y en inteligencia-, que, puesto que obedecen sus órdenes, son capaces de entenderlas y, en esta medida, comparten con ellos la misma comunidad del lenguaje. De esta manera, los obreros demuestran que el hecho de que unos gobiernen y otros obedezcan está fundado en una razón contingente. Los obreros, explica Rancière, deciden "jouer le même jeu que l'adversaire [jugar al mismo juego que su adversario]" (2004a, p. 91), deciden imitar el comportamiento de los hombres libres e iguales. En lugar de denunciar como ilusoria la igualdad inscrita en el preámbulo de la Constitución, como tiende a hacer la crítica marxista de los derechos formales, los obreros deciden verificarla comportándose como si esa igualdad fuera ya efectiva, como si fueran iguales que sus patrones, como si existiera entre ellos un mundo común. En

Una reconstrucción minuciosa de estas modificaciones puede encontrarse en la introducción de Donald Reid (2012) a la traducción americana de La Nuit des prolétaires. 
definitiva, mediante una demostración performativa de capacidad, que es al mismo tiempo una argumentación racional y una exhibición sensible, los obreros adquieren por los hechos el derecho que los patrones les niegan.

Desde el punto de vista de Rancière, cualquier proceso de participación política aparece siempre articulado como una demostración de este tipo: demostración ante quien se niega a escuchar la propia palabra como expresión de racionalidad, pero sobre todo demostración ante uno mismo, confianza en la posibilidad de apropiarse de la palabra y actualizar las propias capacidades racionales sin la tutela de otro individuo. La noción de demostración decanta la definición de la política hacia el terreno de la acción, hacia lo que los individuos son capaces de hacer cuando confían en su propia potencia. Pero, al mismo tiempo, el concepto de demostración permite concebir la praxis como un espacio de racionalidad, como una escena mixta en la que la acción subversiva se canaliza mediante un sistema articulado de razones, mediante una exhibición sensible de las propias demandas como demandas fundadas en justicia. Para ser transgresora, una acción política debe poder fundarse racionalmente. Esto no implica ignorar la violencia y otras dimensiones irracionales del comportamiento humano que suelen acompañar a los procesos de participación política, sino que convierte la palabra racional en un operador de radicalización de la acción: "la parole fonde un droit que la violence ne saurait se donner à elle-même [la palabra funda un derecho que la violencia no podría darse a sí misma]" (Rancière y Faure, 2007, p. 10), escribe Rancière en La parole ouvrière.

Por otra parte, la ventaja de la noción de demostración es que define la agencia política en términos relacionales: no como un proceso autorreferencial del sujeto o del grupo consigo mismos, sino como un proceso heterológico (Rancière, 2004a, p. 121), como un acto de interpelación dirigido a un tercero que se niega a reconocer la legitimidad del conflicto. Los sastres parisinos de 1833 devienen sujetos políticos en la medida en que se demuestran a sí mismos y demuestran a sus patrones que son iguales que ellos, que sus demandas están fundadas en derecho y, por lo tanto, que su violencia es racional exactamente en la misma medida en que es irracional la dominación que se ejerce sobre ellos.

Esta dimensión heterológica de la participación política no está igualmente presente en todos los trabajos de Rancière sobre el movimiento obrero. En otros textos que derivan de su investigación archivística, Rancière parece interesarse más por la dimensión subjetiva que por la dimensión heterológica de la política. Su trabajo sobre el fondo Gauny (2017) es paradigmático en este sentido. En la lectura que propone Rancière de los escritos de este carpintero-filósofo, la subjetivación política no se conceptualiza en términos relacionales, como una demostración de capacidad frente a un otro, sino como un proceso de transformación de sí y de modificación consciente de la propia existencia. Según Rancière, la política de Gauny es ante todo una estética en la que el tema cínico de convertir la propia vida en una obra de arte ocupa un lugar central (no en vano, el filósofo Diógenes es una de las referencias intelectuales de este obrero sansimoniano). En sus opúsculos cenobíticos, Gauny diseña una fascinante contraeconomía doméstica encaminada a restringir el gasto para multiplicar la libertad, a limitar el consumo superfluo con vistas a obtener mayor autonomía, mayores energías, mayor tiempo libre para la propaganda. La economía cenobítica es una ética de la frugalidad que implica una revisión permanente de los recursos destinados a la alimentación, a la vestimenta, al alojamiento y a la higiene personal. Aunque su objetivo es en último término político, como el propio Gauny reconoce, la economía cenobítica establece ante todo una relación reflexiva del individuo consigo mismo, con sus placeres y sus capacidades (Sánchez Santiago, 2021).

Para emancipar a los otros, es necesario comenzar por emanciparse uno mismo. Esta convicción de Gauny es una de las tesis fundamentales de Joseph Jacotot. Si atendemos a la lectura que Rancière propone de su obra en Le Maître ignorant (1987/2004b), este pedagogo revolucionario sostiene que la condición previa de toda política emancipadora consiste en hacer acopio de los propios recursos, pero no de los recursos materiales, sino intelectuales. Para aumentar su potencia política, el individuo debe comenzar por hacer inventario de las competencias intelectuales que posee por defecto (como la propia lengua materna o la habilidad ligada al oficio) y pensar en la manera como las ha obtenido, especie de "retour sur soi qui n'est pas la contemplation pure d'une substance pensante mais l'attention inconditionnée à ses actes intellectuels, à la route qu'ils tracent et à la possibilité d'y avancer toujours en apportant la même intelligence à la conquête de territoires nouveaux" (Rancière, 2004b, p. 64). ${ }^{8}$ ¿Cuánto puede un cuerpo? Su potencia política es proporcional a la autoconciencia que es capaz de desarrollar acerca de sus propias capacidades intelectuales. Un cuerpo desarrolla su potencia política máxima -su emancipación- cuando considera sus propias capacidades como siendo iguales a las de cualquier otro: "L'émancipation est conscience de [l']égalité [la emancipación es conciencia de la igualdad]" (p. 68).

Habrá que esperar a La Mésentente (1995) para volver a encontrar en el centro del análisis la cuestión de la demostración, de la participación política como heterología. Significativamente, la reflexión de Rancière en este trabajo contiene referencias marginales a la obra de Jacotot y la figura de Gabriel Gauny no comparece en ningún momento (cuando tal vez podría haberlo hecho, por ejemplo, como figura prototípica de la subjetivación

Traducción: retorno sobre uno mismo que no es la contemplación pura de una sustancia pensante, sino la atención incondicionada a los propios actos intelectuales, al camino que trazan y a la posibilidad de avanzar en ellos aplicando siempre la misma inteligencia en la conquista de territorios nuevos. 
política entendida como desidentificación, como ruptura con el ethos que define la condición social objetiva del proletariado). Pero La Mésentente introduce un elemento importante en el análisis de la heterología política que no encontramos en "Les usages de la démocratie": el otro por antonomasia, ese tercero ante el cual se lleva a cabo la demostración de capacidad política deja de ser identificado con el patrón o el burgués. En el segundo capítulo de La Mésentente, ese otro recibe un nuevo nombre: Rancière le asignará el nombre general de policía.

Introduciendo la noción de policía y reubicando la cuestión de la emancipación obrera en el problema más general de la democracia, el pensamiento de Rancière renueva su vocabulario y se sitúa en fase con las preocupaciones y las nuevas formas de problematización de la teoría crítica de la década de los noventa.

\section{Democracia intermitente: una definición de la política en diálogo con Foucault}

La noción rancieriana de policía [police] juega deliberadamente con la polisemia. Es difícil saber con seguridad

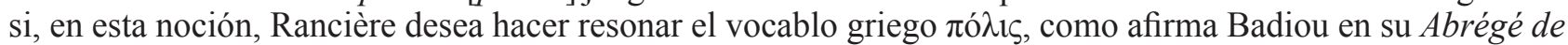
métapolitique (1998, p. 131). Lo que sí parece probable es que el juego conceptual de La Mésentente en torno a las cuestiones de la participación [avoir-part], el reparto de las partes [partage], las partes que participan [la part des parties] y aquellas que son excluidas de la participación [la part des sans-part] remita al problema aristotélico de la distribución de las magistraturas entre las distintas partes de la ciudad, tal y como se analiza en el Libro IV de la Política. Y de lo que no cabe duda es de que el problema fundamental de La Mésentente, el problema de la política o de la existencia paradójica de una parte privada de participación [la part des sanspart], se enuncia en polémica explícita con el proyecto aristotélico de domesticar el démos convirtiéndolo en una parte más de la comunidad, en un partenaire suplementario en la lucha por ocupar los puestos de mando de la ciudad (Rancière, 1995, p. 107 ss.).

Sea como sea, en la obra de Rancière de la década de los noventa, el problema de la participación política se conceptualiza en conexión directa con la noción de policía, una noción que está ausente en sus trabajos sobre el archivo del pensamiento obrero y que, en todo caso, encuentra una formulación preliminar en la crítica de Rancière de la "policía teórica" de Althusser (2011, p. 87).

En La Mésentente, Rancière define la policía así:

La police est, en son essence, la loi, généralement implicite, qui définit la part ou l'absence de part des parties. (...) La police est ainsi d'abord un ordre des corps qui définit les partages entre les modes du faire, les modes d'être et les modes du dire, qui fait que tels corps sont assignés par leur nom à telle place et à telle tâche ; c'est un ordre du visible et du dicible qui fait que telle activité est visible et que telle autre ne l'est pas, que telle parole est entendue comme du discours et telle autre comme du bruit (1995, p. 51). ${ }^{9}$

Hasta cierto punto, la noción de policía intersecta con el concepto foucaultiano de poder, aunque apunta hacia una realidad más amplia. La policía es una estructuración simbólica del espacio social -un partage du sensible - caracterizada por la ausencia de vacío y de suplemento, pues produce una adecuación sin resto entre maneras de ser, ocupaciones y competencias. El diseño platónico del Estado ideal en la República es considerado por Rancière la tentativa teórica más depurada de organización policial de lo sensible, la archipolicía [archipolice] por excelencia (1995, p. 103). El concepto foucaultiano de poder funciona en un nivel inferior. En el interior del espacio sensible recortado por la policía pueden definirse técnicas y estrategias de poder cuyo objetivo consiste en fijar los cuerpos al orden policial, asignándoles una identidad y una función precisas. ${ }^{10} \mathrm{Si}$ la policía delimita el espacio de juego del poder, el poder puede ser comprendido como el soporte material del orden policial y como la garantía de su reproducción indefinida.

Sin embargo, Rancière no desarrolla en ningún lugar un análisis detallado de la manera como la esfera de la policía y la esfera del poder se articulan y se implican recíprocamente, y esta limitación confronta su análisis con dificultades muy relevantes. Pues, por un lado, Rancière parece hacer suya la interrogación foucaultiana sobre las formas de reparto de la visibilidad y la invisibilidad que están en la base de cualquier cuerpo social. De hecho,

Traducción: "En esencia, la policía es la ley, generalmente implícita, que define la participación o la ausencia de participación de las partes (...) La policía es por lo tanto, ante todo, un orden de los cuerpos que define el reparto entre los modos de hacer, los modos de ser y los modos de hablar, que hace que tales cuerpos sean asignados por su nombre a tal lugar y a tal tarea; es un orden de lo visible y lo decible que hace que tal actividad sea visible y que tal otra no lo sea, que tal palabra sea escuchada como discurso y tal otra como ruido." Opto por traducir partie como parte y part como participación. En su traducción de La Mésentente, Horacio Pons prefiere traducir los dos vocablos franceses por el español parte. Pero esta opción no permite acentuar la polisemia del vocablo parte, que significa tanto la porción de un todo [partie] cuanto la parte de un todo que corresponde a cada cual tras efectuar un reparto, la participación que cada uno recibe del todo del que forma parte [part]. Lo importante es que esta diferencia no es solo semántica, sino que concierne a un objetivo sustancial de la teoría de Rancière: analizar la política como un modo paradójico de participación de los que no tienen participación [part] y, por lo tanto, tampoco parte [partie].

10 Comparando su enfoque con el de Foucault, Rancière lo explica así: "Police, chez moi, ne définit pas une institution de pouvoir, mais un principe de partage du sensible à l'intérieur duquel peuvent se définir des stratégies et des techniques de pouvoir [Para mí, la policía no es una institución del poder, sino un principio de reparto de lo sensible en cuyo interior se pueden definir estrategias y técnicas de poder]" (2000b, p. 2). 
reconoce explícitamente el ascendente de Foucault al formular su noción clave de reparto de lo sensible en su obra homónima (2000a, pp. 13-14). Pero, por otro lado, parece pasar por alto que la interrogación foucaultiana acerca de lo visible, lo decible y lo pensable en una sociedad determinada es indisociable de la determinación de los mecanismos de saber/poder que operan en esa sociedad. ¿Se puede identificar adecuadamente un reparto de lo sensible dejando de lado el modo en que las relaciones de saber/poder producen materialmente la sociedad, definiendo en cada caso el lugar, la función y la parte o la ausencia de parte de los individuos?

$\mathrm{Al}$ igual que desborda la analítica foucaultiana del poder, la noción rancieriana de policía designa una realidad más amplia que la que Foucault tematiza con el mismo término en las dos últimas lecciones del curso de 1977-1978 en el Collège de France. Como nos recuerda Rancière en La Mésentente (1995, p. 51), el análisis histórico de Foucault en este curso revela que lo que hoy entendemos por policía no coincide con ninguno de los significados que recibe el término entre los siglos XV y XVIII. Especialmente a partir del siglo XVIII, el término de policía nombra el conjunto de saberes y prácticas encaminadas a acompasar la vida de los seres humanos con el desarrollo de las fuerzas estatales y la estabilidad de su orden interior.

También Rancière considera necesario disociar la policía de la "baja policía" [basse police], de los "coups de matraque des forces de l'ordre et les inquisitions des polices secrètes [los porrazos de las fuerzas del orden y los interrogatorios de las policías secretas]" (Rancière, 1995, p. 51). Pero no lo hace para convertirla en el instrumento mayor de una forma de gobierno concreta e históricamente determinada, característica del siglo XVIII. La policía no es "une fonction sociale mais une constitution symbolique du social. L'essence de la police n'est pas la répression, pas même le contrôle sur le vivant. Son essence est un certain partage du sensible" (2004a, p. 240). ${ }^{11}$ En este punto, parece pertinente la lectura de Mathieu Potte-Bonneville, quien ha apreciado en la noción rancieriana de policía una suerte de principio ahistórico o transhistórico, "un mode de constitution et de sensibilisation du social dont les formes étudiées par Foucault aux XVIIe et XVIIIe siècles constituent un cas exemplaire, mais nullement exclusif' (2006, p. 179). ${ }^{12}$

Este parentesco intelectual con Foucault, que debería abordarse con mayor detenimiento y que sin duda podría ser desarrollado en otras muchas direcciones, ${ }^{13}$ puede ser útil ahora para examinar la conexión entre la noción de policía y la cuestión de la participación política. La policía, hemos dicho, no es el Estado policial, sino su condición transhistórica de posibilidad. Tampoco es el poder, sino la configuración sensible en cuyo interior se ejerce el poder y que, a su vez, este contribuye a delimitar. Por último, ni la policía ni el poder se identifican con la política, que, de acuerdo con la definición de Rancière, posee una racionalidad autónoma y antagónica con respecto a la racionalidad de la policía. ${ }^{14}$ La lógica policial -eventualmente doblada o sostenida por dispositivos de poder-y la lógica política constituyen dos lógicas heterogéneas. Toda la cuestión consiste en saber en qué consiste precisamente esta heterogeneidad: aquí se juega una de las diferencias fundamentales entre las posiciones teóricas de Rancière y Foucault.

Para Foucault, el problema se plantea en términos de inmanencia radical: no existe un afuera de las relaciones de poder. La dialéctica entre el poder y la resistencia debe ser concebida en el interior de un dominio complejo e inestable de relaciones de fuerza de acuerdo con un modelo relacional: cada acto de resistencia implica una reorganización del poder y cada intervención del poder proporciona un punto de apoyo posible para la resistencia. "Les résistances ne relèvent pas de quelques principes hétérogènes (...) Elles sont l'autre terme, dans les relations de pouvoir; elles s'y inscrivent comme l'irréductible vis-à-vis," escribe Foucault en La volonté de savoir (1976, pp. 126-127, cursiva nuestra). ${ }^{15}$ Podría decirse que Foucault pretende estar a la altura de la regla de inmanencia: ninguna racionalidad exterior o principio heterogéneo viene a interrumpir esta relación de complementariedad entre el poder y la resistencia. ${ }^{16}$

Para Rancière, la cuestión se plantea en otros términos. No en términos de trascendencia, por supuesto, sino de heterogeneidad: la lógica policial y la lógica política no son dos polos de una misma relación dialéctica, sino dos procesos heterogéneos entre los que se producen encuentros puntuales, imprevisibles y precarios. En La Mésentente, leemos:

\footnotetext{
Traducción: una función social, sino una constitución simbólica de lo social. La esencia de la policía no es la represión, pero tampoco el control de los seres vivos. Su esencia consiste en un cierto reparto de lo sensible.

12 Traducción: un modo de constitución y sensibilización de lo social con respecto al cual las formas estudiadas por Foucault en los siglos XVII y XVIII constituyen un caso ejemplar, pero de ninguna manera exclusivo.

13 Remito al lector al volumen colectivo coordinado por A. M. Tello (2016).

14 Que la noción foucaultiana de biopolítica tampoco guarda relación alguna con la política en el sentido rancieriano del término es algo que el propio Rancière se ha encargado de puntualizar. Cf. Rancière 2000b, 2000c. Algunos comentaristas han cuestionado el punto de vista de Rancière. Cf., por ejemplo, la introducción de A. M. Tello al volumen citado en la nota anterior.

15 Traducción: Las resistencias no dependen de determinados principios heterogéneos (...) Constituyen el otro término de las relaciones de poder; se inscriben en ellas en un enfrentamiento irreductible.

16 Pienso que, al menos en este aspecto, este modelo de análisis no es objeto de una modificación sustancial con la introducción del problema de la libertad y el gobierno a partir de los cursos de Foucault en el Collège de France de los años 1977-1978 y 1978-1979. En Sécurité, territoire, population (2009a) y en Naissance de la biopolitique (2009b), la libertad no es caracterizada como un derecho natural de los individuos o como un principio externo de limitación del poder, sino como el correlato de los dispositivos securitarios de gobierno. Sobre esta cuestión, me permito remitir al lector a mi trabajo: "La gubernamentalidad como poder a distancia. Foucault y la crisis de las disciplinas" (Sánchez Santiago, 2019).
} 
l'activité politique est toujours un mode de manifestation qui défait les partages sensibles de l'ordre policier par la mise en acte d'une présupposition qui lui est par principe hétérogène, celle d'une part des sans-part, laquelle manifeste elle-même, en dernière instance, la pure contingence de l'ordre, l'égalité de n'importe quel être parlant avec n'importe quel autre être parlant (1995, p. 53, cursiva nuestra). ${ }^{17}$

Para que la política exista, es necesario que en el orden policial intervengan una serie de actos de verificación de la igualdad conducidos por modos de subjetivación específicos. Para que haya política, no basta con desplazar, invertir o modificar estratégicamente el reparto actual de las relaciones de poder. Es necesario que en este reparto se inscriba un principio que le es por principio heterogéneo, el principio de la igualdad, y que lo haga por medio de sujetos específicos. Por eso no puede sostenerse la analogía entre la pareja conceptual poder/resistencia y policía/política, a menudo sugerida en las lecturas comparativas del pensamiento de los dos autores. La lógica de la igualdad no está analíticamente comprendida en la lógica de la policía, sino que implica la constitución a posteriori de una serie de actos que deben ser articulados políticamente, que se sobreimprimen en la realidad como un excedente. ${ }^{18}$ Esta articulación es tarea de sujetos políticos, identidades colectivas que no existen previamente como partes objetivas de la sociedad; este excedente se identifica con el principio de la igualdad. En efecto, se trata de un principio normativo y existen buenas razones para suponer que Foucault tendría dificultades para aceptarlo. Pero este principio presenta una naturaleza bien singular que conviene precisar correctamente.

Rancière ha tomado buena nota de la lección antiesencialista de Foucault y de ninguna manera podría postular un universal abstracto susceptible de encarnarse en las leyes o de transformarse en un objetivo asintótico de la práctica de gobierno. En la perspectiva de Rancière, la igualdad no viene a imponerse al mundo desde el exterior, sino que se encuentra en cierto modo ya ahí, operando como la condición de posibilidad de la desigualdad del orden policial. Para que un inferior obedezca las órdenes de su superior -es una de las demostraciones que aporta Rancière (1995, p. 78)-, es necesario ante todo que ese inferior comprenda que se trata de una orden y que debe obedecer; y, si el inferior es capaz de comprender al superior, esto quiere decir que "participe à la même communauté des êtres parlants, qu'il est, en cela, son égal. Il s'en déduit, en bref, que l'inégalité des rangs sociaux ne fonctionne qu'en raison de l'égalité même des êtres parlants." 19 La igualdad no es un principio trascendente, sino un presupuesto que debe ser verificado prácticamente, una premisa cuyas consecuencias deben ser demostradas performativamente por medio de escenas de disenso específicas. La igualdad es un "opérateur de démonstrations [operador de demostraciones]," escribe Rancière (2004a, p. 116).

La política, en el sentido que le atribuye Rancière, consiste en la inscripción de la igualdad en el orden policial, en la visibilización o puesta en escena de sujetos y objetos que no eran previamente reconocidos en un determinado reparto policial de lo sensible. Esta hibridación necesaria entre la lógica política y la lógica policial es el elemento que pierden de vista las interpretaciones de Rancière en clave arendtiana o anarquista. El asunto ha sido explicado con mucha solvencia por Chambers (2013, p. 45ss.). Para Rancière no hay -no puede haber- un lugar puro de la política. "Pour qu'il y ait politique, il faut que la logique policière et la logique égalitaire aient un point de rencontre [Para que haya política, es necesario que la lógica policial y la lógica igualitaria encuentren un punto de contacto]" (1995, p. 57). La participación democrática consiste -y se agota- en la inscripción de la demanda igualitaria en el orden policial-desigualitario, en la reconfiguración de los datos sensibles de un orden policial históricamente determinado.

En definitiva, la filosofía de Rancière, como la de Foucault, se sigue moviendo en el plano de la inmanencia, pero sin dejar de reconocer la posibilidad de inscribir en la realidad social formas de acción, modos de subjetivación y mundos de significación heterogéneos o excedentarios, autónomos con respecto a las relaciones de poder.

La ventaja del paradigma de Rancière es que sitúa el foco del análisis en la política al margen de las formas instituidas del poder, en la democracia como una acción humana específica que posee su propia racionalidad. A diferencia de Maquiavelo y algunos de sus herederos, Rancière trata de disociar el concepto de la política del problema de la conquista y la conservación del poder del Estado. Una y otra poseen lógicas heterogéneas. Análogamente al modo en que Foucault analiza el poder al margen de la teoría jurídico-política de la soberanía y la axiomática marxista de la dominación, en cuya cúspide se sitúa el poder estatal, Rancière trata de pensar la política como una actividad que no se identifica con el orden del Estado, sino con las acciones disensuales que interrumpen el orden policial, del que el aparato de Estado es tan solo una parte (un efecto de un régimen de gubernamentalidad más complejo, por plantear la cuestión en términos foucaultianos).

17 Traducción: la actividad política es siempre un modo de manifestación que deshace los repartos sensibles del orden policial mediante la actualización de una presuposición que le es por principio heterogénea, la de una participación de quienes carecen de participación, una presuposición que, en último término, manifiesta por sí misma la pura contingencia del orden, la igualdad de cualquier hablante con cualquier otro.

18 Anders Fjeld ha apuntado en el mismo sentido: "Rancière invita a repensar la subjetivación política resituándola en la problemática de la emancipación e introduciendo dos elementos que faltan en Foucault: por una parte, la idea de que la ruptura del orden social no está precodificada por el poder, sino que lo desborda; por otro, la idea de que el campo social se encuentra de antemano fragmentado por dispositivos heterogéneos, en lugar de estar recubierto por un poder plástico y maleable" (2017, pp. 5-6).

19 Traducción: participa de la misma comunidad de hablantes, que, al menos en esto, es igual que él. Se deduce, en definitiva, que la desigualdad de los rangos sociales solo funciona a causa de la igualdad misma de los hablantes. 
El inconveniente -y, para muchos de sus intérpretes, el resultado decepcionante- de su análisis es que no prevé ningún protocolo de estabilización institucional de los procesos de participación política. La política democrática es "un accident toujours provisoire dans l'histoire des formes de la domination [un accidente siempre provisional en la historia de las formas de la dominación]" (Rancière, 2004a, p. 238, 1995, p. 37). Esta manera de presentar las cosas parece emparentar a Rancière con una percepción de la democracia como un hecho fugaz y espontáneo, como una realidad infrecuente que no acaba nunca de cristalizar en instituciones estables y duraderas. Una democracia intermitente, en definitiva, cuya existencia se agota en los efectos puntuales que es capaz de producir. Pero veremos a continuación que las cosas son algo más complejas.

\section{El sorteo como inscripción institucional de la igualdad}

Rancière articula una teoría radical que - esto es innegable- descarta de antemano la posibilidad de identificar la democracia con un conjunto sólido de instituciones y prácticas de gobierno: para el autor de La Haine de la démocratie, nuestros regímenes políticos no pueden ser calificados en rigor como democracias, sino como Estados de derecho oligárquicos $(2005$, p. 81). Sin embargo, una lectura cabal de sus planteamientos no debería tomar este enunciado como una conclusión, sino como la premisa de un argumento más elaborado que Rancière desarrolla en varios lugares y que, si se analiza con detenimiento, impide caracterizar su enfoque como anti-institucionalista, anarquista o contrario a cualquier forma jurídica o estatal. ${ }^{20}$ Es obvio que Rancière destina esfuerzos decididos a pensar la política -la democracia- al margen del poder y sus formas instituidas, como una suerte de contrapoder antioligárquico, pero no ignora que algunas de estas formas constituyen de hecho una cristalización jurídico-política de la acción democrática y sirven a su vez como garantía para su ejercicio. El Estado o el Derecho no son formas puras, sino sistemas heterogéneos en los que la lógica política ha venido a incidir históricamente inscribiendo en ellos conquistas igualitarias de las que, a su vez, pueden extraer su impulso ulteriores acciones democráticas. Ya en La Mésentente, Rancière aclara que las formas de la democracia no son "indifférentes à l'existence d'assemblées élues, de garanties institutionnelles des libertés d'exercice de la parole et de sa manifestation, de dispositifs de contrôle de l'État. Elles y trouvent les conditions de leur exercice et elles les modifient en retour. Mais elles ne s'y identifient pas" (1995, p. 141). ${ }^{21}$

El sufragio universal, la escuela, la sanidad y los transportes públicos son ejemplos de estas formas híbridas, a medio camino entre la policía y la política, que Rancière analiza en sus textos (Rancière, 2005, p. 62). Estas realidades tienen su germen en procesos efectivos de participación política. Son conquistas democráticas que han sido codificadas jurídico-políticamente en forma de leyes e instituciones,

modes d'inscription hybride de l'égalité et de la lutte politique dans le système social de répartition des pouvoirs et des fonctions. (...) Les transports publics ou la Sécurité sociale, l'hôpital ou l'école publique, la possibilité pour celui qui n'est rien de se déplacer, d'apprendre ou d'être soigné à l'égal de celui qui est quelque chose, c'est cela même, cette visibilité de l'égalité dans le concret de notre univers, qui est de plus en plus mal supporté par les maîtres de notre monde (2009, pp. 52-53).22

El instrumento del sorteo es otra de las formas híbridas que resultan del entrecruzamiento de la lógica policial con la lógica política. Por un lado, el sorteo solo tiene sentido en un régimen institucional-representativo policial, en el sentido de Rancière-que distingue entre sujetos que mandan y sujetos que obedecen y que somete a los primeros a la elección de los segundos; pero, al mismo tiempo, el sorteo posee la virtud democratizadora la virtud política- de organizar esta elección en unas condiciones determinantes de aleatoriedad. En un proceso de selección por sorteo, cualquier individuo sin excepción, o al menos cualquier individuo elegible, puede ser elegido para un determinado cargo. Cualquier individuo sin excepción: esto significa que no existe ninguna esencia, capacidad o título natural o adquirido que predisponga a un grupo de individuos para ejercer el poder y a otro grupo de individuos para prestar obediencia. Significa que el poder no está fundado en naturaleza y que, por consiguiente, la distribución entre quienes mandan y quienes obedecen es completamente contingente. Reconociendo la elección aleatoria de los cargos políticos, la lógica policial que distribuye jerárquicamente a los individuos en el cuerpo social se ve forzada a acoger en su seno un principio extraño, el principio de la igualdad, que declara la arbitrariedad de cualquier forma de jerarquía y habilita a cualquier individuo para

20 Entre las investigaciones que han subrayado esta idea, merecen ser destacados los trabajos de Laura Quintana (2013; 2018) y Anders Fjeld (Fjeld y Tassin, 2015).

21 Traducción: no son indiferentes a la existencia de asambleas electas, de garantías institucionales de las libertades de ejercicio de la palabra y de su manifestación o de dispositivos de control del Estado. Encuentra en ellas las condiciones de su ejercicio y a su vez las modifica. Pero no se identifica con ellas.

22 Traducción: modos de inscripción híbrida de la igualdad y la lucha política en el sistema social de reparto de los poderes y las funciones. (...) Los transportes públicos o la Seguridad social, el hospital o la escuela pública, la posibilidad de desplazarse, aprender o curarse para quien no es nadie en igualdad con quien es alguien; es exactamente esto, esta visibilidad de la igualdad en la concreción de nuestro universo la que soportan cada vez peor los dueños de nuestro mundo. 
participar indistintamente de las funciones de mando y obediencia. El sorteo es un virus igualitarista instalado en el corazón mismo de las instituciones.

A partir del año 2000, Rancière parece verse seducido por el sorteo como una herramienta que permite democratizar las instituciones introduciendo en ellas condiciones equitativas para el acceso al gobierno y al uso legítimo de la palabra. ${ }^{23}$ No es casual la fecha en la que Rancière acoge el instrumento del sorteo en su teorización sobre la política. La primera referencia la encontramos en La Haine de la démocratie, un texto de 2005 escrito al calor del referéndum sobre la Constitución europea, aprobada en Francia a pesar de los votos en contra de la mayoría de la población. Ante la perplejidad de las élites gubernamentales y la opinión mediática, el pueblo electoral respondió al referéndum ejerciendo su soberanía en un sentido inesperado, entendiendo "que la question était une vraie question, qu'elle relevait non de l'adhésion de la population mais de la souveraineté du peuple et que celui-ci pouvait donc y répondre non aussi bien que oui" (Rancière, 2005, $\mathrm{p}$. 87 ss.). ${ }^{24}$ En este caso, el pueblo francés se comportó "comme une population de tirage au sort [como una población de sorteo]" (2005, p. 62), afirma Rancière.

En En quel temps vivons-nous ?, publicado en 2017, el tema del sorteo se tematiza de una forma más nítida en el contexto de una discusión sobre los movimientos asamblearios y los nuevos partidos políticos de izquierda surgidos tras la crisis financiera de 2008. En esta conversación con su editor, el escrito Éric Hazan, Rancière se refiere explícitamente al sorteo como un dispositivo que permite "mettre plus de démocratie dans les institutions [introducir más democracia en las instituciones]" (2017, p. 8) reconociendo la competencia política de cualquiera para ocuparse de los asuntos comunes. En realidad, esta idea viene a completar un argumento que Rancière había desarrollado ya en La Haine de la démocratie. En este texto, el "anarquista" Rancière propone un conjunto de reglas y procedimientos destinados a evaluar la calidad democrática de nuestros sistemas representativos y a contrarrestar su funcionamiento naturalmente oligárquico: "mandats électoraux courts, non cumulables, non renouvelables, monopole des représentants du peuple sur l'élaboration des lois ; interdiction aux fonctionnaires de l'État d'être représentants du peuple; réduction au minimum des campagnes et des dépenses de campagne et contrôle de l'ingérence des puissances économiques dans les processus électoraux" $(2005$, p. 80$){ }^{25}$

Rancière lo ha expresado con rotundidad en varias intervenciones: el problema no son las instituciones, sino las instituciones policiales, la privatización de las instituciones comunes en favor de los intereses de las élites políticas y económicas. En cambio, las instituciones que interesa conservar y promover son las que tienen por objetivo la extensión del poder de la gente común, aquellas en las que los procesos de participación democrática han logrado inscribir sus demandas igualitaristas: "Une institution politique en ce sens est une institution qui a pour but l'accroissement du pouvoir de n'importe qui" [Una institución política, en este sentido, es una institución que tiene por objetivo la ampliación del poder de cualquiera] (2012b, p. 217).

El sorteo cumple todos los requisitos para poder ser considerado un dispositivo institucional de amplificación de la lógica igualitaria. Rancière $(2005$, p. 54) lo considera nada menos que la esencia misma de la democracia. Apoyándose en el importante trabajo de reconstrucción histórica llevado a cabo por Bernard Manin en Principes du gouvernement représentatif (cit. en Rancière, 2005, p. 49, n. 29), Rancière explica que, a lo largo de la historia política occidental, el sorteo ha desempeñado un papel relevante en el diseño institucional de regímenes de gobierno muy diversos, desde la democracia ateniense a las Repúblicas italianas de Venecia y Florencia. ${ }^{26}$ En estos sistemas políticos, no necesariamente democráticos en todos sus aspectos, el sorteo permitió abrir un espacio para la demostración de la igualdad y la intervención de cualquiera en los procesos de discusión públicos. Si, para la sensibilidad contemporánea, el mecanismo del sorteo es sinónimo de arbitrariedad e incompetencia y se considera que debe estar restringido a ámbitos del Estado muy puntuales, como el sistema judicial, es porque la historia de las ideas políticas ha perdido de vista el significado originario de la democracia al identificarla con el proceso de elección de representantes. Pero la elección no es "une forme démocratique par laquelle le peuple fait entendre sa voix. (...) L'évidence qui assimile la démocratie à la forme du gouvernement représentatif, issu de l'élection, est toute récente dans l'histoire. La représentation est dans

23 Conviene aclarar en este punto que el sorteo, entendido como elección aleatoria de cargos de representación política, es tan solo uno de los sentidos que recibe el concepto en la filosofía de Rancière. En textos como las "Dix thèses sur la politique," de 1996 (publicado en $2004 a$ ), el tema del sorteo aparece vinculado con el análisis de la democracia como un modo determinado de formación de sujetos políticos desprovistos de títulos de gobierno: en este sentido, la democracia es el poder de los incompetentes, el poder manifestado por una población aleatoria de individuos cualquiera. Y, todavía anteriormente, podría considerarse que la cuestión del sorteo está implícitamente contenida en los desarrollos que Rancière dedica al tema general de la igualdad - de la contingencia de las posiciones sociales- como dato fundamental sobre el que se asienta cualquier orden sensible de distribución de los cuerpos.

24 Traducción: que la pregunta era una pregunta de verdad, que no dependía de la adhesión de la población, sino de la soberanía del pueblo, y que, en esta medida, el pueblo podía tanto responder que sí como responder que no.

25 Traducción: mandatos electorales cortos, no acumulables ni renovables; monopolio de los representantes del pueblo sobre la elaboración de las leyes; prohibición a los funcionarios del Estado de ser representantes del pueblo; reducción de las campañas electorales y los gastos de campaña al mínimo y control de la injerencia de las potencias económicas en los procesos electorales.

26 Para un análisis de la obra de Manin en su conexión con Rancière, cf. Moreno Pestaña y Carballo Rodríguez (2020). 
son origine l'exact opposé de la démocratie. (...) La "démocratie représentative" peut sembler aujourd'hui un pléonasme. Mais cela a d'abord été un oxymore" (Rancière, 2005, pp. 60-61). ${ }^{27}$

En la esencia de la idea democrática no está la elección de representantes competentes para el ejercicio de las funciones de gobierno, sino justamente el principio del sorteo, la posibilidad de que gobiernen quienes no poseen ninguna competencia para gobernar: ni virtud, ni inteligencia, ni riqueza, ni propiedad. El procedimiento del sorteo garantiza que cualquier individuo pueda participar de los asuntos comunes con independencia de los títulos que pueda presentar como aval de su capacidad, que a todos los individuos sin distinción les sea reconocida una capacidad política e intelectual igual para tomar parte en los procesos de deliberación pública. El sorteo es un procedimiento netamente igualitarista que arrebata el gobierno y las instituciones a sus pretendidos dueños naturales, haciendo entrar en ellas a sujetos sin cualidad, a individuos cuyo único título es la ausencia absoluta de título para ejercer el poder. En el fundamento del poder, el sorteo introduce la anarquía: "Démocratie veut dire d'abord cela: un "gouvernement" anarchique, fondé sur rien d'autre que l'absence de tout titre à gouverner [Democracia quiere decir ante todo esto: un "gobierno" anárquico, no fundado sobre ningún otro principio que la ausencia de cualquier título para gobernar]" (Rancière, 2005, p. 48).

Es ciertamente llamativo que, en la secuencia argumentativa de La Haine de la démocratie, sea precisamente un crítico implacable de la democracia como Platón el que sirva de aval a la defensa que hace Rancière del sorteo. El principal rasgo del sorteo que Rancière pone en valor es su capacidad para evitar lo que constituye para Platón la peor desgracia para el Estado: que gobiernen quienes desean gobernar. El sorteo permite acceder al poder a aquellos que no tienen un interés particular en ocuparlo y, por lo tanto, favorece figuras de liderazgo menos despóticas, más neutrales y no necesariamente más incompetentes que las que actualmente ocupan el poder. Por esta última razón, el sorteo no debe ser considerado un procedimiento utópico. Es un procedimiento decididamente realista por cuanto considera la competencia real (es decir, la incompetencia) de la mayor parte de quienes acceden al poder en los regímenes liberalesparlamentarios actuales. Dicho de otra manera: adoptar el sorteo para la elección de los cargos políticos es asumir sin ingenuidad que, en las condiciones actuales, "la sélection des plus aptes est la sélection des plus aptes à se faire sélectionner [la elección de los más aptos es la elección de los más aptos para hacerse elegir]," por decirlo con Castoriadis (1996, p. 16).

Sin dejar de reconocer el alcance filosófico de las ideas de Rancière, Moreno Pestaña ha puesto de manifiesto la débil reconstrucción histórica en la que se asienta su recuperación de la herramienta del sorteo. Por un lado, en la democracia ateniense, la selección aleatoria de los cargos no tenía el funcionamiento anárquico que el análisis de Rancière parece sugerir, sino que estaba bien codificada y sometida a reglas: solo se decidían por sorteo aquellos cargos que no requerían una competencia específica y solo eran elegibles los ciudadanos censados y mayores de una determinada edad. Tampoco es sostenible históricamente el argumento de que el sorteo permitiera acceder al poder a aquellos individuos que no deseaban ejercerlo. En realidad, en Atenas, las candidaturas a los cargos elegidos por sorteo eran voluntarias (Moreno Pestaña, 2019a, p. 431).

Además de una reconstrucción histórica más fina, lo que se echa en falta en el enfoque de Rancière es una exploración más exhaustiva de los efectos igualitaristas del sorteo. Una suspicacia excesiva hacia los proyectos políticos "reformistas" le impide reconocer la verdadera revolución democrática que promete el sorteo e identificar algunos de sus efectos transformadores más evidentes. Nos corresponde a nosotros teorizarlos pensando con Rancière más allá de Rancière. Mencionemos solo algunos como conclusión: ${ }^{28}$ además de permitir gobernar a los incompetentes, la selección aleatoria de los cargos impide la formación de grupos de presión capaces de influir en las decisiones gubernamentales; incentiva el compromiso cívico de los individuos; promueve la heterogeneidad de los participantes en los procesos de discusión pública y los impele a confrontarse con puntos de vista diferentes, y eventualmente a cambiar de opinión; permite prescindir de especialistas en cargos que no requieren de ninguna competencia específica, y, en esta medida, excluye a los "especialistas artificiosos" (Moreno Pestaña y Carballo Rodríguez, 2020, p. 184); reconoce la capacidad de cualquier individuo para formarse un juicio político pertinente en el curso de los procesos de deliberación o durante el ejercicio mismo de sus funciones; y, por último, proporciona un instrumento de transformación moral, pues estimula la autorresponsabilidad de los individuos y los incita a desempeñar correctamente su función, a estar a la altura del puesto para el que han sido elegidos: puede llegar a ser, en definitiva, una pieza esencial de esa paideia democrática que Castoriadis consideraba la condición imprescindible de la igualdad política efectiva (Castoriadis, 1996, p. 284).

Traducción: una forma democrática mediante la que el pueblo hace escuchar su voz. (...) La evidencia que asimila la democracia con la forma de gobierno representativo salido de la elección es muy reciente en la historia. En su origen, la democracia es exactamente lo opuesto de la representación (...) La "democracia representativa" puede parecer hoy un pleonasmo. Pero fue primero un oxímoron.

28 Me apoyo en varias ideas de J. L. Moreno Pestaña (2019a, 2019b, 2020). Sobre la cuestión más general de la igualdad como principio susceptible de realizarse en prácticas, instituciones y formas de vida concretas y materiales, remito al lector a las inspiradoras reflexiones de César Rendueles en su último libro (2020). 


\section{Conclusiones}

Los temas del pensamiento de Rancière analizados en este trabajo interpelan de forma muy directa nuestro presente. Ofrecen un amplio repertorio de conceptos para leer la experiencia política de los últimos diez años en ambos lados del Atlántico y presentan un poder muy singular para informar las prácticas y las aspiraciones de los movimientos sociales contemporáneos. Pero, además, el pensamiento de Rancière proporciona un modelo de análisis novedoso del problema de la participación política. Aunque Rancière es reacio a integrar este concepto en su vocabulario filosófico, su producción teórica desde la década de los ochenta puede ser interpretada como una larga meditación sobre el significado y las formas posibles de participar en política, sobre los mecanismos de exclusión que deniegan a la mayoría el derecho a tomar parte y sobre el sistema social de privilegios que concentra el ejercicio del poder en las manos de unos pocos. Desde Aux bords $d u$ politique hasta sus textos posteriores al año 2000, esta meditación no ha dejado de producir nuevos conceptos $\mathrm{y}$ formas originales de problematización.

La noción de demostración permite analizar la participación al margen de la lógica representativa y las formas instituidas del poder e interpretar los procesos de lucha política como un encadenamiento de acciones performativas de demostración de la igualdad. Según Rancière, el contenido político de una acción no se mide en la cantidad de violencia que contiene o en los efectos espectaculares que es capaz de producir. La política no requiere de barricadas para existir. Requiere de la formación de una instancia colectiva de subjetivación que manifiesta su existencia declarando su igualdad, su capacidad para nombrar lo justo y lo injusto y para deliberar racionalmente acerca del destino de la comunidad. La noción de demostración pone definitivamente el acento en lo que los individuos son capaces de hacer cuando toman conciencia de su igualdad y deciden extraer de este principio todos sus efectos posibles. A esta conciencia de capacidad, que presupone la igualdad de cualquier individuo con cualquier otro, Rancière la denomina "confiance" [confianza] (2004a, p. 111).

La noción de democracia intermitente, la segunda figura de la participación política que hemos analizado, permite hacer más compleja la relación entre la acción popular y la lógica institucional, entre la política y la policía en el sentido que Rancière atribuye a estos términos. En este trabajo se ha defendido que Rancière no puede ser calificado simple y llanamente como un pensador anti-institucionalista. Rancière no impugna las instituciones, sino las instituciones policiales, aquellas que favorecen la concentración del poder en las manos de un reducido número de individuos y bloquean el acceso de la mayoría a los procesos de deliberación pública. Tampoco ignora que las instituciones no son entidades puramente policiales, sino formas híbridas en las que se libra un conflicto permanente entre la lógica policial-desigualitaria y la lógica política-igualitaria. Instituciones como la educación o la sanidad públicas y derechos sociales como los que plasman nuestros ordenamientos jurídicos tienen su origen en procesos efectivos de participación democrática y, a su vez, son un hito de progreso igualitarista en el que pueden tomar apoyo nuevas luchas sociales. En consecuencia, Rancière no entiende la participación política como algo que se produce al margen de un orden institucional, sino como una secuencia de acciones que cuestiona y reordena democráticamente estas o aquellas instituciones policiales. La política democrática actúa siempre sobre un orden policial históricamente determinado. Por eso es intermitente: no porque no ocurra casi nunca, sino porque ocurre siempre en el interior de un orden policial concreto, porque adopta la forma modesta de una interrupción local de estructuras específicas de dominación.

Con sus referencias al dispositivo del sorteo, la tercera figura de la participación política que ha sido analizada, Rancière da un paso más allá en su análisis del binomio política-policía. Aunque sus desarrollos a este respecto son fragmentarios y poco exhaustivos, permiten reflexionar acerca del margen posible de democratización que soportan nuestras instituciones. Entendido, en un sentido técnico, como una herramienta de selección aleatoria de cargos políticos, el sorteo amplía la participación a individuos que carecen de una competencia específica para gobernar. Es un principio de crítica inmanente inscrito en el interior mismo de las instituciones policiales que puede actuar como contrapeso de su tendencia inercialmente oligárquica. Si ser gobernados por instituciones más o menos policiales no es un asunto indiferente, y Rancière no considera que lo sea (1995, p. 53-54), entonces es fundamental explorar los mecanismos que pueden permitir una democratización efectiva de las instituciones y una extensión del poder de cualquiera a todas las estructuras posibles de la sociedad.

Precisamente hacia este objetivo apuntan las fuerzas parlamentarias y extraparlamentarias que, desde la crisis financiera de 2008, luchan por que el desorden económico mundial no arrastre consigo una vuelta al orden ideológico reaccionario. Desde la primavera árabe y los movimientos Occupy hasta los recientes estallidos sociales en Chile y Ecuador, pasando por el 15-M y sus secuelas institucionales en España, lo que se dibuja es un escenario global de contestación del orden dominante en el que la igualdad, el poder de la gente común, la ampliación de los mecanismos de participación política y la reapropiación colectiva de las instituciones se sitúan en el primer plano del debate público. La filosofía de Rancière proporciona valiosos esquemas de análisis para acercarse a estas nuevas realidades, para captar su singularidad y sus posibilidades. Una teoría que lo explica todo, que no encuentra ningún objeto que se le resista, es una teoría fallida (Rancière, 2012 b, p. 100). Pero ocurre algunas veces que la teoría se prolonga en su presente histórico con naturalidad y sin artificios, que es la propia inercia de la realidad la que extrae de ella sus efectos más radicales. La fuerza del pensamiento de Rancière es la fuerza de las experiencias que lo traducen, lo cuestionan y lo revitalizan. 


\section{Bibliografía}

Badiou, Alain (1998). Abrégé de métapolitique [Compendio de metapolítica]. Seuil.

Bosteels, Bruno (2006). La leçon de Rancière: Malaise dans la politique ou on a raison de se mésentendre [La lección de Rancière. Malestar en la política o es razonable estar en desacuerdo]. En L. Cornu y P. Vermeren (eds.): La philosophie déplacée. Autour de Jacques Rancière (pp. 49-70). Horlieu.

Castoriadis, Cornelius (1996): La montée de l'insignifiance. Les carrefours du labyrinthe, vol. 4 [El ascenso de la insignificancia. Las encrucijadas del laberinto, volumen 4]. Points Seuil.

Chambers, Samuel (2013). The lessons of Rancière [Las lecciones de Rancière]. Oxford University.

Fjeld, Anders, \& Tassin, É. (2015). Subjectivation et désidentification politiques. Dialogue à partir d'Arendt et de Rancière [Subjetivación y desidentificación políticas. Diálogo a partir de Arendt y Rancière]. Ciencia Política, 10(19), pp. 193223.

Fjeld, Anders (2017). Modes de subjectivation et post-marxisme [Modos de subjetivación y post-marxismo]. CriDIS Working Papers, $\mathrm{n}^{\mathrm{0}} 67$.

Foucault, Michel (1976). Histoire de la sexualité I. La volonté de savoir [Historia de la sexualidad I. La voluntad de saber]. Gallimard.

Foucault, Michel (2009a). Seguridad, territorio, población (Trad. Horacio Pons). Fondo de Cultura Económica.

Foucault, Michel (2009b). Nacimiento de la biopolítica (Trad. Horacio Pons). Akal.

Gauny, Gabriel (2017). Le philosophe plébéien. Textes rassemblés et présentés par Jacques Rancière [El filósofo plebeyo. Textos reunidos y presentados por Jacques Rancière]. La Fabrique.

Keucheyan, Razmig (2017). Hémisphère gauche: une cartographie des nouvelles pensées critiques [Hemisferio izquierda: un mapa de los nuevos pensamientos críticos]. La Découverte.

May, Todd (2008). The political thought of Jacques Rancière: Creating Equality [El pensamiento político de Jacques Rancière: creando la igualdad]. Pennsylvania State University.

May, Todd (2016). Anarquismo de Foucault a Rancière. En A. M. Tello (ed.): Gobierno y desacuerdo. Diálogos interrumpidos entre Foucault y Rancière. Communes.

Moreno Pestaña, José Luis (2019a). Castoriadis, Rancière: quels apports pour une philosophie du tirage au sort en politique? [Castoriadis, Rancière: ¿qué aportaciones para una filosofía del sorteo en política?]. Participations, número especial, pp. 417-435.

Moreno Pestaña, José Luis (2019b). Retorno a Atenas. La democracia como principio antioligárquico. Siglo XXI.

Moreno Pestaña, José Luis \& Carballo Rodríguez, Francisco Manuel (2020). Geometría, sorteo y política: Jacques Rancière entre Cornelius Castoriadis y Bernard Manin. Isegoría, 62, pp. 169-190.

Mouffe, Chantal (2012). La paradoja democrática. El peligro del consenso en la política contemporánea (Trad. Tomás Fernández Aúz y Beatriz Eguibar). Gedisa.

Potte-Bonneville, Mathieu (2006). Versions du politique. Jacques Rancière, Michel Foucault [Versiones de lo político. Jacques Rancière, Michel Foucault]. En L. Cornu y P. Vermeren (Eds.): La philosophie déplacée. Autour de Jacques Rancière (pp. 169-192). Horlieu.

Quintana, Laura (2013). Institución y acción política: una aproximación desde Jacques Rancière. Revista Pléyade, 11, pp. 143-158.

Quintana, Laura (2018). Más allá de algunos lugares comunes: repensar la potencia política del pensamiento de Jacques Rancière. Isegoría, 59, pp. 447-468.

Rancière, Jacques (1990). En los bordes de lo político (Trad. Alejandro Madrid-Zan y José Grossi). Escuela de Filosofía Universidad ARCIS. Edición digital.

Rancière, Jacques (1995). La Mésentente: politique et philosophie [El desacuerdo: política y filosofía]. Galilée.

Rancière, Jacques (2000a). Le partage du sensible: esthétique et politique [El reparto de lo sensible: estética y política]. La Fabrique.

Rancière, Jacques (2000b). Biopolitique ou politique ? [¿Biopolítica o política?]. Multitudes, no 21.

Rancière, Jacques (2000c). Entretien avec Jacques Rancière [Entrevista con Jacques Rancière]. Le Philosophoire, 13, pp. $29-42$.

Rancière, Jacques (2004a). Aux bords du politique [En los bordes de lo político]. Folio.

Rancière, Jacques (2004b). Le Maître ignorant. Cinq leçons sur l'émancipation intellectuelle [El maestro ignorante. Cinco lecciones sobre la emancipación intelectual] (trabajo original publicado en 1987). 10/18.

Rancière, Jacques (2005). La Haine de la démocratie [El odio de la democracia]. La Fabrique.

Rancière, Jacques (2009). Moments politiques: interventions 1977-2009 [Momentos políticos: intervenciones 19772009]. La Fabrique.

Rancière, Jacques (2011). La leçon d'Althusser [La lección de Althusser]. La Fabrique.

Rancière, Jacques (2012a). La Nuit des prolétaires: archives du rêve ouvrier [La noche de los proletarios: archivos del sueño obrero] (trabajo original publicado en 1981). Fayard/Pluriel.

Rancière, Jacques (2012b). La méthode de l'égalité: entretiens avec Laurent Jeanpierre et Dork Zabunyan [El método de la igualdad: entrevistas con Laurent Jeanpierre y Dork Zabunyan]. Bayard.

Rancière, Jacques (2017). En quel temps vivons-nous? [¿En qué tiempo vivimos?]. La Fabrique. 
Rancière, Jacques, \& Faure, Alain (2007). La parole ouvrière [La palabra obrera]. La Fabrique.

Reid, Donald (2012). Introduction [Introducción]. En J. Rancière: Proletarian nights: the workers'dream in nineteenthcentury France. Verso.

Rendueles, César (2020). Contra la igualdad de oportunidades. Un panfleto igualitarista. Seix Barral.

Ruby, Charles (2007/2). Le sens de l'action dans la philosophie de Jacques Rancière [El sentido de la acción en la filosofía de Jacques Rancière]. Le Philosophoire, 29, pp. 165-182.

Ruby, Charles (2009). L'interruption. Jacques Rancière et la politique [La interrupción. Jacques Rancière y la política. La Fabrique.

Sánchez Santiago, Alfredo (2019). La gubernamentalidad como poder a distancia. Foucault y la crisis de las disciplinas. Daimon. Revista Internacional de Filosofia, 76, pp. 155-170.

Sánchez Santiago, Alfredo (2021). Un precario del siglo XIX: explotación laboral y reapropiación de sí en los escritos de Gabriel Gauny. En Nuria Sánchez Madrid (Ed.), La filosofía social ante la precariedad: genealogías, resistencias, diagnósticos. La Catarata.

Tello, Andrés Maximiliano (Ed.). (2016). Gobierno y desacuerdo. Diálogos interrumpidos entre Foucault y Rancière. Communes.

Vermeren, Patrice (2018). La filosofía interrumpida (Discurso de Patrice Vermeren en la ceremonia de entrega del grado Honoris Causa de la Universidad de Chile). Accesible en: https://www.uchile.cl/portal/noticias/noticias-porunidad/148483/filosofia-interrumpida-de-patrice-vermeren [consultado el 1 de marzo de 2021]. 